\title{
Basic research: an economic good
}

A new survey of the literature of economics and social aspects of science gives support to commonly held beliefs about the value of 'blue-skies' research.

As sciences go, economics may be dismal, while in many people's eyes the sociology of science can seem downright absurd. But when both are used to show that government support for basic science is economically an excellent thing, respect for them can only soar. How testable is that conclusion - and how strong?

The Science Policy Research Unit at the University of Sussex has performed a useful service by surveying the literature on the benefits of government support for basic research, and on related policies in various countries. (The report - The Relationship between Publicly Funded Basic Research and Economic Performance, by Ben Martin et al. - was sponsored by the UK Treasury.) The report describes the state of the evidence by which economic benefits can be tested. The result, encouragingly, is support for ideas that most researchers, but not everybody in finance ministries, would have wishfully taken for granted. When examined critically, they emerge all the stronger.

The idea that the knowledge that emerges from basic research is its principal - let alone its sole - public benefit is becoming more questionable. Just how public is the benefit? That knowledge, once published, can be picked up by others only partially, and then not for free, given the trained individuals and specialized equipment required. Scientists may take this for granted, but economists have underestimated the costs of this 'public' knowledge by concentrating on costs of production and neglecting those of use. The role of information technology is ambiguous: the Internet is enhancing the availability of information, but increased use of computation and simulation strengthens the less publicly available but no less economically significant product of basic research, the tacit skills of researchers. And the evidence is there to highlight the economic usefulness of ex-researchers in esoteric science as much as those in catalysis and biotechnology.

What emerge clearly from this survey are the persistent uncertainties in attempts to quantify the economic returns on public expenditure on basic research - the benefits arising from the use of the knowledge gained and in the employment of those trained. Work by Edwin Mansfield, who examined the industrial utilization of academic research in 75 major US companies, is much quoted - and naively so, to judge by the report's list of "heroic" assumptions made in Mansfield's study. But the firm conclusion remains that the economic returns on society's investment are substantiated and substantial, and that several per cent of the companies' sales would not have been achieved without university research.

Other benefits can be analysed. Surveys of industrialists clarify the importance of the transfer of instrumentation, which can underpin new disciplines or can amount to an industry in itself. But the economic benefits remain to be quantified. More progress has been made on the impact of basic research on the ability of business to find new solutions to technological problems. In biotechnology, the impact of basic research is direct. In other disciplines, the path from discovery to innovation is less clear cut. But the evidence points to substantial direct and indirect benefits nevertheless. And a clear advantage of geographical proximity in industrial/academic collaboration has emerged. A country that wishes to stimulate high-tech industrial growth would do particularly well to encourage strong regional networks.

To get the best out of such networks, companies must support research themselves, have their employees publish original work, and be in contact with the community. And the idea is emerging that the research network itself should be seen as a significant unit of economic public good.

Little of this will surprise those whose occupation is research. But providing tangible evidence lessens one's dependence on faith. The unsurprising disappointment in the report, acknowledged by the authors themselves, is that, while giving nothing but comfort to the idea that basic research is economically a good thing, it gives no help at all to governments trying to assess the benefits of one level of funding rather than another.

\section{In search of anger}

Road transport should be on trial. New proposals on air quality suggest that it is not.

CARBON monoxide, nitrogen dioxide, sulphur dioxide, benzene, 1,3 butadiene, lead and poison-coated soot. As a result of some of those, ozone. And hence bronchial illness, lymphomas, leukaemia, heart attacks...

There is a much that road transport has to answer for. But however proudly it might proclaim its introduction of the tightest airquality standards in Europe (come 2005), the United Kingdom government, like so many others, has manifestly failed to bring the manufacturers and owners of cars, trucks and buses to book. Its "air quality strategy" announced last week (see page 743) does not deserve that grandiloquent title. It is dependent on future regulation by the European Union, and undermined by a stated intention to take into account the costs of any proposed initiatives: it will invite manufacturers and haulage associations to spell out such costs in detail before decisions are taken on how the new standards - some of which, it turns out, are droppable - will be achieved. More determination is required than that.

The first priority must be the policing of emissions from older vehicles. Any car three years old or more should have to pass an annual test of its exhaust, while traffic police should have the power to stop and inspect vehicles for dirty emissions and, if necessary, issue fume tickets with fines proportional to the scale of excess.

Another priority is the imposition of additional cost on car use. Here the UK government has done something tangible, with steadily increasing duties on petrol. But the continuing use of company cars as a perk should cease, while financial penalties should be suffered by those who drive in cities out of convenience rather than necessity. Manufacturers and purchasers of cars will have to accept an increase in costs too.

Such initiatives would be perceived to make sense by a public more conscious of what it is suffering. People ingesting soot, sulphur dioxide and the rest of it should be angrier than they are. But the only time Europeans, at least, have got angry about petrol was when an oil rig was about to be allowed to sink to the ocean floor. If that is a test of the achievements of green organizations, then they have failed indeed. 